\title{
Directional dispersal patterns of Chorthippus parallelus (Orthoptera: Acrididae) in patches of grazed pastures
}

\author{
TIM GARDINER AND JULIAN HILL
}

(TG) Centre for Environment \& Rural Affairs (CERA), Writtle College, Chelmsford, Essex, UK, CM1 3RR. Email: tg@writtle.ac.uk

(JH) Faculty of Applied Science and Technology, Writtle College, Chelmsford, Essex, UK, CMI 3RR.

\begin{abstract}
A small-scale study investigating the directional dispersal patterns of Chorthippus parallelus in a grazed pasture was undertaken in 2002 and 2003. The study site was divided into 4 quadrants with a central release circle. Nymphs and adults were marked, released and resighted at varying intervals throughout the day, when the distance and direction moved (taken from the center) were recorded for each individual. Significant directional movements to the north of the release circle were evident for both nymphs and adults. These movements were probably in response to habitat factors and topography outside of the release area. Both nymphs and adults moved uphill from the heavily grazed 'spatially hostile' release circle, to patches of tall ungrazed grass beyond the release area. These patches of ungrazed grass could have afforded shelter, from predation and inclement weather, not provided by the short vegetation inside the release area.
\end{abstract}

\section{Keywords}

mark-recapture, grasshopper dispersal, movement, pasture

\section{Introduction}

Grasshopper dispersal is influenced by climatic stimuli such as temperature, polarized light in the sky (Homberg 2004), wind direction (Narisu et al. 1999) and habitat factors including vegetation height and topography (Richards \& Waloff 1954). Grasshoppers are therefore likely to display directional movements in response to the interaction of climatic and habitat factors in heterogeneous environments in the field. In simplistic terms, directional dispersal of grasshoppers may be resource-led (Samways 1994); however, environmental factors such as direction of prevailing wind do play a role (Narisu et al. 1999).

Seasonal displacement of grasshoppers away from sites of eclosion in short grass to habitats where food and shelter occur (tall vegetation) have been observed (Uvarov 1977). However at the end of the summer, mature adults may return to the areas of short vegetation and bare earth to oviposit. The cues for this behavior are complex and relate not only to nutritional resources, but to microclimatic and reproductive strategies of the grasshoppers. Population density may also affect dispersal, with increased densities of insects leading to greater probability of dispersal (Narisu et al. 1999).

In mark-recapture experiments, 50 Omocestus viridulus L. adults (25 of each sex) were marked on the pronotum with yellow paint and released at a central point (Southwood \& Waloff 1967). Twenty-eight (58\% of the total) marked adults were recaptured a week later, with the mean distance moved $6.7 \mathrm{~m}$ for males and $4.3 \mathrm{~m}$ for females. Though little detail is provided on the cues for directional dispersal, this study does suggest that adult $O$. viridulus are sedentary and tend to move very short distances if the habitat is favorable.

In a study by Narisu et al. (1999) conducted on rangeland grasshoppers, there was a strong tendency for direction-oriented dispersal. In this case, the adult grasshoppers moved predominantly upwind in a northwest direction, possibly instigated by a search for nutritional resources or for mates. In contrast, nymphal instars did not demonstrate directional movement, having perhaps a lower need for searching for nutritional resources. This suggests a "trade-off" between sedentary behavior in favorable habitats during nymphal instars and dispersal behavior as response to reproductive or nutritional cues as adults.

The aim of the present paper is to investigate the directional dispersal of nymphal and adult Chorthippus parallelus Zetterstedt in an extensively grazed pasture in the UK and to discuss the possible cues for any directional movements.

\section{Methods}

The method used for this experiment was modified from Narisu et al. (1999). Narisu et al. used fluorescent powder to mark grasshoppers in the field in their mark-recapture experiment. In the study reported in this paper, $C$. parallelus nymphs and adults were marked using water-soluble paint of various colors. Grasshoppers were caught and marked using a simple 2-tube device. The larger diameter tube (outer sleeve) had a 4-mm mesh fixed to one end. The smaller diameter tube (inner sleeve) had a sponge pad fixed to one end. Individual grasshoppers were placed in the larger diameter tube and gently held against the mesh with the sponge pad on the smaller diameter tube. Grasshoppers were then easily marked on the pronotum (Southwood \& Waloff 1967) using a small paint brush. It took the author approximately 1 to $2 \mathrm{~min}$ to mark and release each individual.

The study site was established in extensively managed grassland grazed by sheep ( 8.5 sheep/ha: United Kingdom OS grid reference TL672069, Chelmsford, Essex, UK). It was divided into 4 equal quadrants with a release circle of 3-m radius (Fig. 1) in the center, in a design similar to that of Narisu et al. (1999). The dominant vegetation species in each quadrant were the grasses Cynosurus cristatus and Lolium perenne.

Sward heights and slopes of the 4 quadrants were surveyed in early June 2002, before the mark-recapture experiment commenced, to ensure the site was fairly homogenous in vegetation structure and topography. Along the diagonal bisecting each quadrant, a line of ten $1-\mathrm{m}^{2}$ quadrats was established at $1-\mathrm{m}$ intervals starting from the center of the release circle (Fig. 1). Four sward heights 


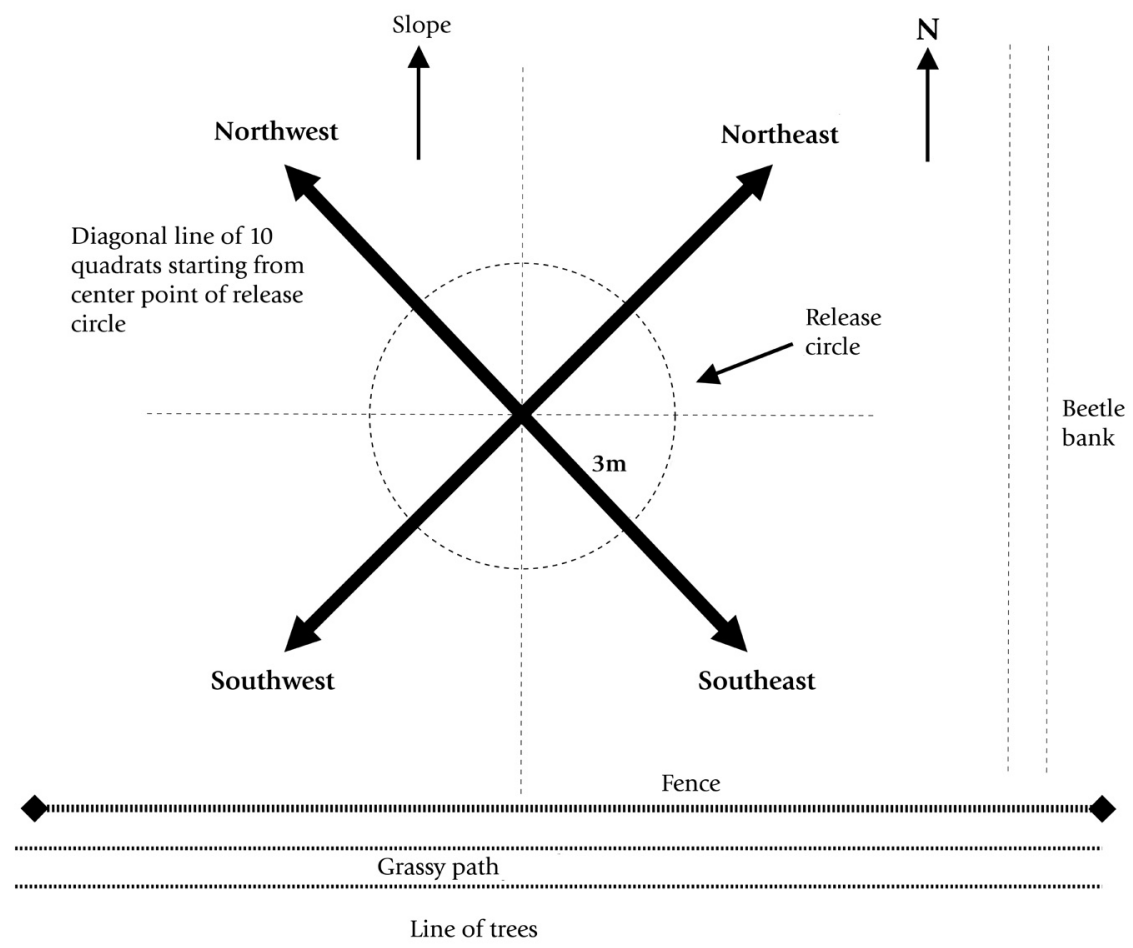

Fig. 1. Layout of the dispersal experiment showing the four quadrants. were recorded in each of the 10 quadrats in every quadrant using a Drop Disc (Smith et al. 1993). The weighted disc (200 g, $300 \mathrm{~mm}$ diameter) was dropped from the top of a vertical meter rule and the height of the vegetation where the disc settled was recorded in $\mathrm{mm}$. To determine the topography of the site, the difference in the elevation of the soil surface (in $\mathrm{cm}$ ) from the center point of the release circle was also measured in the center of each quadrat, using a simple levelling technique (Malcolm 1926).

Immediately before the introduction of marked individuals, all grasshoppers present in the release area were collected using a sweep net and removed. Twenty marked grasshoppers were then released into the center circle at approximately $1000 \mathrm{~h}$. The calculated stocking density of grasshoppers in the release area was 0.70 individuals $/ \mathrm{m}^{2}$ similar to observed C. parallelus densities reported by Gardiner et al. (2002) in grassland habitats in the Chelmsford area. Grasshoppers were visually resighted at 2-h intervals after release at $1200,1400,1600$ and $1800 \mathrm{~h}$. The resighting process started on each occasion with a search of the entire release area for $2 \mathrm{~min}$ and then each 1-m increment outside of the release circle was searched for $2 \mathrm{~min}$. The search was terminated as soon as no grasshoppers were resighted in the 1-m increment surveyed or the observer was a maximum of $10-\mathrm{m}$ from the center point of the release circle. No direct search was made for grasshoppers that had moved further than $10-\mathrm{m}$ from the center point of the release circle. All resighting was conducted by the same observer using a standard procedure in which the vegetation was slowly swept back and forth with a pole to cause any marked grasshoppers to be recorded upon disturbance.

The mark-recapture procedure was performed on 3 separate days using nymphs of all instars, and on 3 more days using adults, in both 2002 and 2003 (a total of 6 occasions for both nymphs and adults). Weather conditions were recorded when the marked grasshoppers were released at 1000 and then immediately before each resighting occasion throughout the day. Cloud cover was recorded using oktas ( 0 -8 scale: e.g., 8 oktas $=$ complete cloud cover, $4=50 \%$ cloud cover, $0=$ no cloud cover; File 1991), wind speed $(\mathrm{m} / \mathrm{s})$ using an electronic gauge and temperature $\left({ }^{\circ} \mathrm{C}\right)$ at $1 \mathrm{~m}$ above the ground. Wind direction was also recorded.

\section{Statistical analysis}

To determine whether dispersal was directional or random at the study site, the data for all nymphs and adults resighted were pooled for each quadrant and subjected to chi-square $\left(\chi^{2}\right)$ analysis under a null hypothesis that equal numbers of grasshoppers should be recaptured in all quadrants. The sedentary natures of nymphs and adults were compared by assessing the total number of nymphs and adults resighted inside the release circle, and the total number resighted outside, for each quadrant, using chi-square $\left(\chi^{2}\right)$ analysis under a null hypothesis that equal numbers of grasshoppers should be resighted inside and outside the release circle in each quadrant. Grasshoppers resighted within the release circle were considered to be sedentary, while those seen outside were seen as dispersing to other areas of the site.

In addition to the direction of dispersal, the mean dispersal distance was also analysed for each quadrant. Grasshoppers located within the release circle were assumed to have moved $1.5 \mathrm{~m}$ (half the radius). Individuals resighted outside the release circle were assumed to have moved from the center point of the release area $(1.5 \mathrm{~m}+1-\mathrm{m}$ increments). This method of data analysis is described in Narisu et al. (1999).

Mean dispersal distances per quadrant, separate for nymphs and adults, were calculated by summing the distances moved by every individual nymph or adult resighted in the quadrant, divided by the total number of individuals of each life stage resighted within each quadrant. Mean dispersal distances for both nymphs and adults (data for 2002 and 2003 pooled) in each quadrant were compared using a one-way ANOVA. Tukey's test was then performed to ascertain if mean distances of dispersal differed by quadrant.

The rate of dispersal of both nymphs and adults in each quadrant was calculated as the mean dispersal distance during the periods 
1000 to 1200,1200 to 1400,1400 to 1600 and 1600 to $1800 \mathrm{~h}$. To assess if the rate of dispersal increased in each quadrant over the course of the experimental day, the mean dispersal distance at 1200 ( $2 \mathrm{~h}$ after release) was compared with the mean dispersal distance at 1800 ( $8 \mathrm{~h}$ after release) using Student's t-test. All statistical analyses were performed using SPSS Version 10 (SPSS 1999) according to the methods of Mead et al. (1993).

\section{Results}

Meteorological conditions. - The prevailing direction of wind during the mark-recapture study was from the southwest (Table 1). Wind speed was generally higher during the nymphal dispersal period than during that of the adult ( 3.37 vs $2.39 \mathrm{~m} / \mathrm{s}$ respectively). The maximum wind speed recorded was $7.1 \mathrm{~m} / \mathrm{s}$ on 23 July 2002 (nymph experimental day). Mean temperature was also slightly higher during the adult experimental days compared with the conditions during nymph experiments (25.0 vs $21.6^{\circ} \mathrm{C}$ respectively). Many of the survey days were cloudy (medial cloud cover of 6 oktas), notably 23 July (nymphs) and 20 August 2002 (adults).

\section{Characteristics of the study site}

Sward height.-Sward height varied little within the release area (Fig. $2)$; at greater distances from the center of the release circle along the diagonal bisecting each quadrant, the northeast and northwest quadrants had taller vegetation than the southeast and southwest quadrants (mean sward heights outside of the release circle were $70,78,41$, and $44 \mathrm{~mm}$ for the northeast, northwest, southeast and southwest quadrants respectively). The maximum sward height was $115 \mathrm{~mm}$ at $10 \mathrm{~m}$ from the center point of the release circle in the northwest quadrant.

Slope.-The soil surface within the release circle was relatively even (Fig. 3). However, outside of the release circle a gentle upwards slope was evident in both the northeast and northwest quadrants, whereas the southeast and southwest quadrants had fairly uniform topography.
Resighting rates and directional dispersal

Resighting rates were much higher for nymphs (288 out of 480 possible resights, $60 \%$ ) than for adults (215 out of 480 possible resights, $44.8 \%$ ) suggesting greater mobility in adult grasshoppers compared to nymphs. Directional movements of both nymphs and adults were evident in this study (Fig. 4). A total of 125 nymphs (43.4\% of resighted individuals) were observed within the northwest quadrant, whereas, very few were located within the southeast (only 24 or $8.3 \%$ of re-observed individuals) indicating a nonrandom distribution of resighted nymphs throughout the quadrants $\left(\chi^{2}=\right.$ 71.36 , d.f. $=3, \mathrm{p}<0.01)$. Movements of adults in a northerly direction were pronounced during the experiment with 177 resightings ( $82.3 \%$ of resighted individuals) in the northeast and northwest quadrants combined, reflecting a nonrandom distribution of adults during the mark and re-observe period $\left(\chi^{2}=116.03\right.$, d.f. $\left.=3, \mathrm{p}<0.01\right)$.

A total of 72 nymphs (25\% of resighted individuals) and 20 adults (9.3\% of re-observed individuals) were located in the southwest quadrant, representing movement into the prevailing wind (Fig. 4). A total of 67 nymphs (23.2\%) and 62 adults (28.8\%) were resighted in the northeast quadrant, which indicated downwind movement.

\section{Analysis of mobility}

The total number of nymphs resighted inside the release area ( 181 or $62.8 \%$ of re-observed individuals) was higher $\left(\chi^{2}=19.01\right.$, d.f. $=1, \mathrm{p}<0.01$ ) than the number resighted outside (107 or $37.2 \%$ of re-observed individuals, Table 2) suggesting the more sedentary nature of immature instars. Nymphs were particularly sedentary in the southeast and southwest quadrants, where more individuals were resighted inside the release circle than outside (Table 2). However, in the northeast and northwest quadrants of the study site, the number of nymphs re-observed outside the release circle was higher than the number re-observed inside the release area 8 $h$ after release (at 1800).

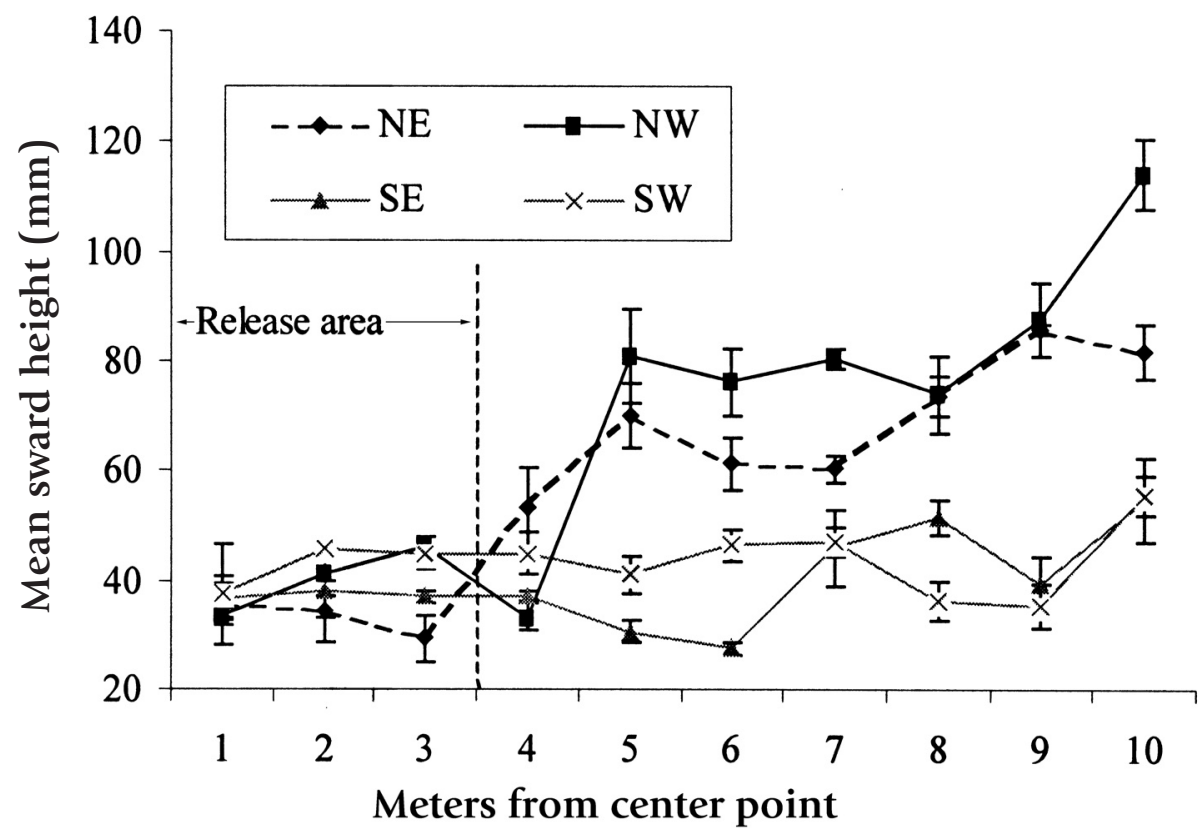

Fig 2. Mean sward height at 1-m intervals from the center of the release circle in each quadrant. 


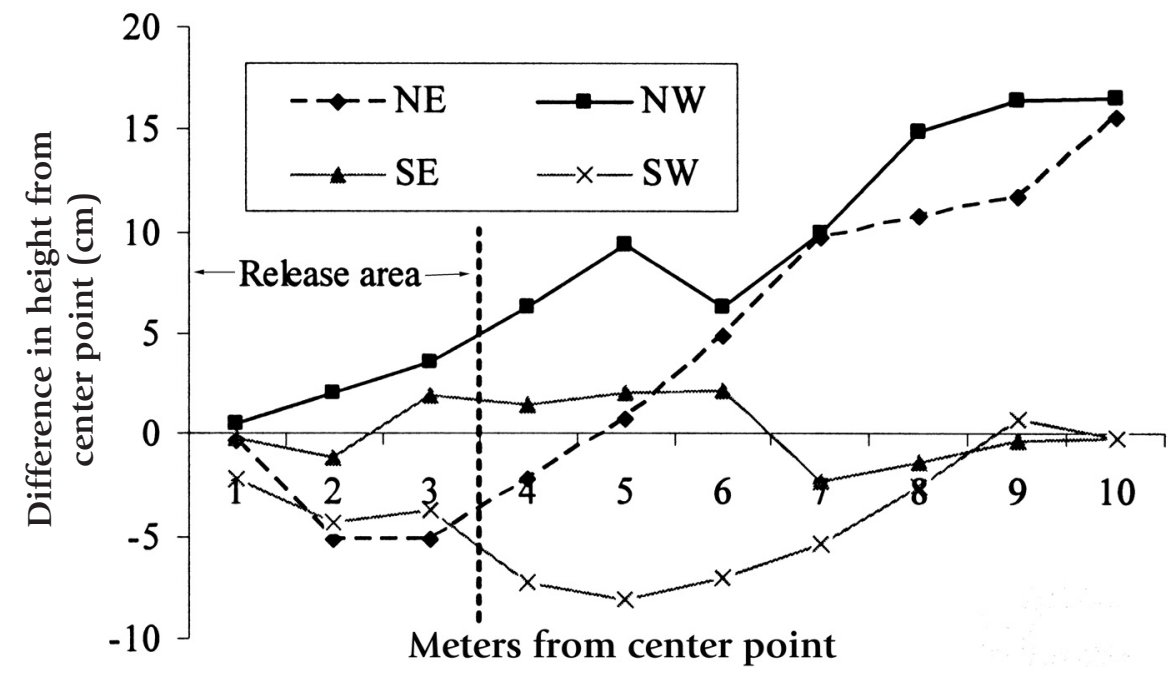

Fig 3. Difference in height of soil surface from the center of the release circle at 1-m intervals in each quadrant.

The total number of adults resighted inside the release circle (92 or $42.8 \%$ of re-observed individuals) was lower $\left(\chi^{2}=4.47\right.$, d.f. $=1, \mathrm{p}<0.05)$ than the number re-observed outside the release site (123 or $57.2 \%$ of re-observed individuals), indicating that adults were more mobile than nymphs. Adults were particularly mobile in the northwest quadrant, where significantly more individuals were resighted outside the release circle than inside (Table 2). In fact, more individuals were resighted outside the release circle than inside at 1400, 1600 and $1800 \mathrm{~h}$ in the northwest quadrant, indicating that adults were particularly quick to disperse in this direction.

\section{Mean dispersal distance}

The mean distance of dispersal for nymphs was greatest in the northeast and northwest quadrants (Table 3). However, only the mean distance of dispersal in the northwest quadrant was significantly greater (F statistic: 8.28 , d.f. $=287, \mathrm{P}<0.05$ ) than the southeast and southwest quadrants. Similarly, the mean dispersal distance for adults was greatest in the northeast and northwest quadrants, although the only significant difference in mean distance was between the northwest and southwest quadrants (F statistic: 3.05, d.f. $=214, \mathrm{p}<0.05)$.

\section{Rate of dispersal}

The dispersal rate increased throughout the course of the experimental day in all quadrants (Table 4). Increases between mean rate of dispersal between 1200 and $1800 \mathrm{~h}$ were evident for nymphs in the northwest quadrant $(\mathrm{p}<0.05)$ and adults in the northeast and northwest quadrants (both $\mathrm{p}<0.05$ ).

\section{Discussion}

Narisu et al. (1999) suggested that directional movements of grasshoppers in rangeland habitats may be related to the direction of the prevailing wind. In their study, adults moved predominantly into the prevailing northwesterly wind, and it was suggested that the movement upwind may have reflected the search for resources such as feeding sites or mates. In the study reported in this paper both nymphs and adults of $C$. parallelus displayed directional dispersal within a small area of extensively grazed pasture and a high proportion of adults and nymphs were re-observed in pasture northwest of the release site, which was neither into or with the prevailing wind (Fig. 4).

C. parallelus nymphs were observed moving upwind and downwind in fairly equal proportions at the study site (Fig. 4). Lockwood (2004) states that the maximum wind velocity that early instar nymphs are able to jump into is $2.3 \mathrm{~m} / \mathrm{s}$ and that high wind speeds may cause nymphs to lose ground when jumping. The mean wind speed recorded on 4 of the 6 survey days in this study was greater than the figure stated by Lockwood (2004), therefore it is quite possible that nymphs were carried downwind into the northeast quadrant when jumping occurred. Narisu et al. (2000) showed that late instar nymphs $\left(4^{\text {th }}, 5^{\text {th }}\right)$ in rangelands moved upwind. However, in this study nymphs were particularly sedentary in the upwind southwest quadrant (Tables 2-4), indicating that nymphs did not display a strong response to olfactory cues in the pasture, perhaps due to the relatively low mobility of nymphs on the windy survey days.

Wind direction and speed may have had a more significant impact on adults at the study site. The results show that $31 \%$ of adults were resighted in the northeast quadrant, suggesting that jumping adults were carried downwind towards the tall ungrazed patches of grass to the northeast of the release area (Fig. 4). A very small proportion of adults were resighted in the upwind southwest quadrant (Fig. 4) and dispersal distance was lower than in the northeast and northwest quadrants (Table 3 ). Therefore adults were not responding to olfactory cues transported on the prevailing southwesterly wind in this study.

Other factors such as compass orientation of insects in response to the earth's magnetic field and skylight polarization may have played a role in the northerly movements of $C$. parallelus adults at the study site (Fig.4). One hypothesis is that these movements to the north

Table 1. Weather conditions recorded during the nymph and adult experimental days $\left( \pm \mathrm{S}_{\overline{\mathrm{X}}}\right)$.

\begin{tabular}{|c|c|c|}
\hline \multirow[b]{2}{*}{ Weather variable } & \multicolumn{2}{|c|}{ Life stage } \\
\hline & Nymph & Adult \\
\hline Modal wind direction & Southwest & Southwest \\
\hline Mean wind speed $(\mathrm{m} / \mathrm{s})$ & $3.37 \pm 0.32$ & $2.39 \pm 0.27$ \\
\hline Mean temperature $\left({ }^{\circ} \mathrm{C}\right)$ & $21.57 \pm 0.78$ & $24.97 \pm 0.66$ \\
\hline $\begin{array}{l}\text { Median cloud cover } \\
\text { (oktas) }\end{array}$ & 6 & 6 \\
\hline
\end{tabular}


Table 2. Total number of $C$. parallelus nymphs and adults resighted inside/outside the release area at different times of the day.

\begin{tabular}{lcccccc}
\hline \multirow{2}{*}{ Life stage } & \multicolumn{6}{c}{ Quadrant } \\
\hline Nymph & Time & Northeast & Northwest & Southeast & Southwest & Total \\
& 1200 & $16 / 5$ & $19 / 9$ & $7 / 0$ & $24 / 6$ & $66 / 20$ \\
& 1400 & $11 / 6$ & $23 / 12$ & $8 / 0$ & $12 / 2$ & $54 / 20$ \\
& 1600 & $8 / 7$ & $12 / 18$ & $3 / 1$ & $9 / 5$ & $32 / 31$ \\
& 1800 & $6 / 8$ & $9 / 23$ & $5 / 0$ & $9 / 5$ & $29 / 36$ \\
\hline Adult & Total no & $41 / 26$ & $63 / 62$ & $23 / 1$ & $54 / 18$ & $181 / 107$ \\
& $\chi^{2}$ value & 3.36 & 0.01 & $20.17^{* *}$ & $18.00^{* *}$ & $19.01^{* *}$ \\
\hline & 1200 & $13 / 9$ & $19 / 14$ & $3 / 1$ & $7 / 0$ & $42 / 24$ \\
& 1400 & $4 / 8$ & $9 / 19$ & $3 / 2$ & $2 / 0$ & $18 / 29$ \\
& 1600 & $4 / 10$ & $9 / 24$ & $3 / 1$ & $5 / 5$ & $21 / 40$ \\
& 1800 & $3 / 11$ & $4 / 17$ & $4 / 1$ & $0 / 1$ & $11 / 30$ \\
\hline & Total no & $24 / 38$ & $41 / 74$ & $13 / 5$ & $14 / 6$ & $92 / 123$ \\
& $\chi^{2}$ value & 3.16 & $9.47^{* *}$ & 3.56 & 3.20 & $4.47^{*}$ \\
\hline
\end{tabular}

* significant at $\mathrm{p}<0.05$

** significant at $\mathrm{p}<0.01$

may be attributable to orientation within the earth's magnetic field, with the insect orienting to magnetic north. Compass orientation has been suggested as a possible cause for directional movements of migrating insects (Williams 1958) and has been established as a possible factor in butterfly migration (Taylor \& Taylor 1984). However, Williams (1958) noted that migration patterns of Schistocerca gregaria Forsk. were not affected when subjected to a very strong magnetic field. It is unlikely that the nonmigratory grasshopper $C$. parallelus is influenced to any great extent by the earth's magnetic field, although compass orientation may be important for largescale movements of migratory species.

The field cricket Gryllus campestris L. has been shown to gain directional information from the polarization of light in the sky (Labhart 1999), using specialized ommatidia located in the dorsal rim of its compound eyes (Labhart \& Meyer 1999, Labhart \& Meyer 2002). Polarized light is also picked up in the dorsal rim of the compound eyes of Acridids such as S. gregaria. Mappes \& Homberg (2004) suggest that the perception of polarized light is also important for compass navigation of this species. However, when navigating under adverse sky conditions, grasshoppers may have to use other orientation guides such as landmarks (Labhart 1999) or habitat structures.

To minimise environmental factors (vegetation height, botanical composition and slope) the selection of a uniform release circle was
Table 3. Mean dispersal distance $(\mathrm{m})$ in each quadrant for 2002 and 2003 combined $\left( \pm s_{\overline{\mathrm{X}}}\right)$.

\begin{tabular}{lcc}
\hline & \multicolumn{2}{c}{ Life stage } \\
Quadrant & Nymph & Adult \\
\hline Northeast & $2.23 \pm 0.13^{\mathrm{ab}}$ & $2.74 \pm 0.18^{\mathrm{ab}}$ \\
Northwest & $2.62 \pm 0.13^{\mathrm{b}}$ & $2.87 \pm 0.12^{\mathrm{b}}$ \\
Southeast & $1.54 \pm 0.04^{\mathrm{a}}$ & $2.28 \pm 0.35^{\mathrm{ab}}$ \\
Southwest & $1.97 \pm 0.12^{\mathrm{a}}$ & $2.00 \pm 0.22^{\mathrm{a}}$ \\
\hline F value & 8.28 & 3.05 \\
\hline
\end{tabular}

Significant differences at $\mathrm{p}<0.05$ between mean values with different superscript letters in each column (ANOVA)

necessary before the release of marked grasshoppers. The release area had been heavily grazed by sheep and the sward height in this area was below $50 \mathrm{~mm}$ (Fig. 2). Gardiner et al. (2002) suggest that C. parallelus is most numerous in swards of $100-200 \mathrm{~mm}$ in height and less numerous in short $(<100 \mathrm{~mm})$ and tall $(>200 \mathrm{~mm})$ vegetation. Therefore, the release circle was unsuitable for this species, having a short sward that provides no cover from avian predators or inclement weather conditions. This heavily grazed environment was 'spatially hostile' (Rogers 1984) for both C. parallelus nymphs and adults. Both life stages would therefore have a greater chance of survival and breeding success in a more suitable environment and dispersal away from the release circle was a necessity for large

Table 4. Mean dispersal distance $(\mathrm{m})$ in each quadrant at $1200,1400,1600$ and $1800 \mathrm{~h}( \pm \mathrm{S} \overline{\mathrm{x}})$.

\begin{tabular}{|c|c|c|c|c|c|}
\hline \multirow[b]{2}{*}{ Life stage } & \multirow[b]{2}{*}{ Time } & \multicolumn{4}{|c|}{ Quadrant } \\
\hline & & Northeast & Northwest & Southeast & Southwest \\
\hline \multirow[t]{5}{*}{ Nymph } & 1200 & $1.88 \pm 0.18$ & $2.04 \pm 0.17$ & $1.50 \pm 0$ & $1.77 \pm 0.11$ \\
\hline & 1400 & $2.09 \pm 0.21$ & $2.15 \pm 0.19$ & $1.50 \pm 0$ & $1.71 \pm 0.15$ \\
\hline & 1600 & $2.50 \pm 0.31$ & $2.97 \pm 0.26$ & $1.75 \pm 0.25$ & $2.14 \pm 0.27$ \\
\hline & 1800 & $2.64 \pm 0.35$ & $3.31 \pm 0.30$ & $1.50 \pm 0$ & $2.50 \pm 0.47$ \\
\hline & $\mathrm{t}$ value & -1.97 & $-3.72^{*}$ & NA & -1.53 \\
\hline \multirow[t]{5}{*}{ Adult } & 1200 & $2.31 \pm 0.24$ & $2.20 \pm 0.17$ & $1.75 \pm 0.25$ & $1.50 \pm 0$ \\
\hline & 1400 & $2.50 \pm 0.33$ & $2.71 \pm 0.20$ & $2.50 \pm 0.63$ & $1.50 \pm 0$ \\
\hline & 1600 & $2.93 \pm 0.42$ & $3.38 \pm 0.26$ & $2.75 \pm 1.25$ & $2.30 \pm 0.39$ \\
\hline & 1800 & $3.43 \pm 0.46$ & $3.36 \pm 0.32$ & $2.10 \pm 0.60$ & $3.50 \pm 0$ \\
\hline & $\mathrm{t}$ value & $-2.13^{*}$ & $-3.23^{*}$ & -0.54 & NA \\
\hline
\end{tabular}

* Significant differences at $\mathrm{p}<0.05$ between mean values for 1200 and $1800 \mathrm{~h}$.

$\mathrm{NA}=\mathrm{t}$-test not applicable due to lack of data. 
Fig 4. The total number of nymphs and adults resighted in each quadrant.

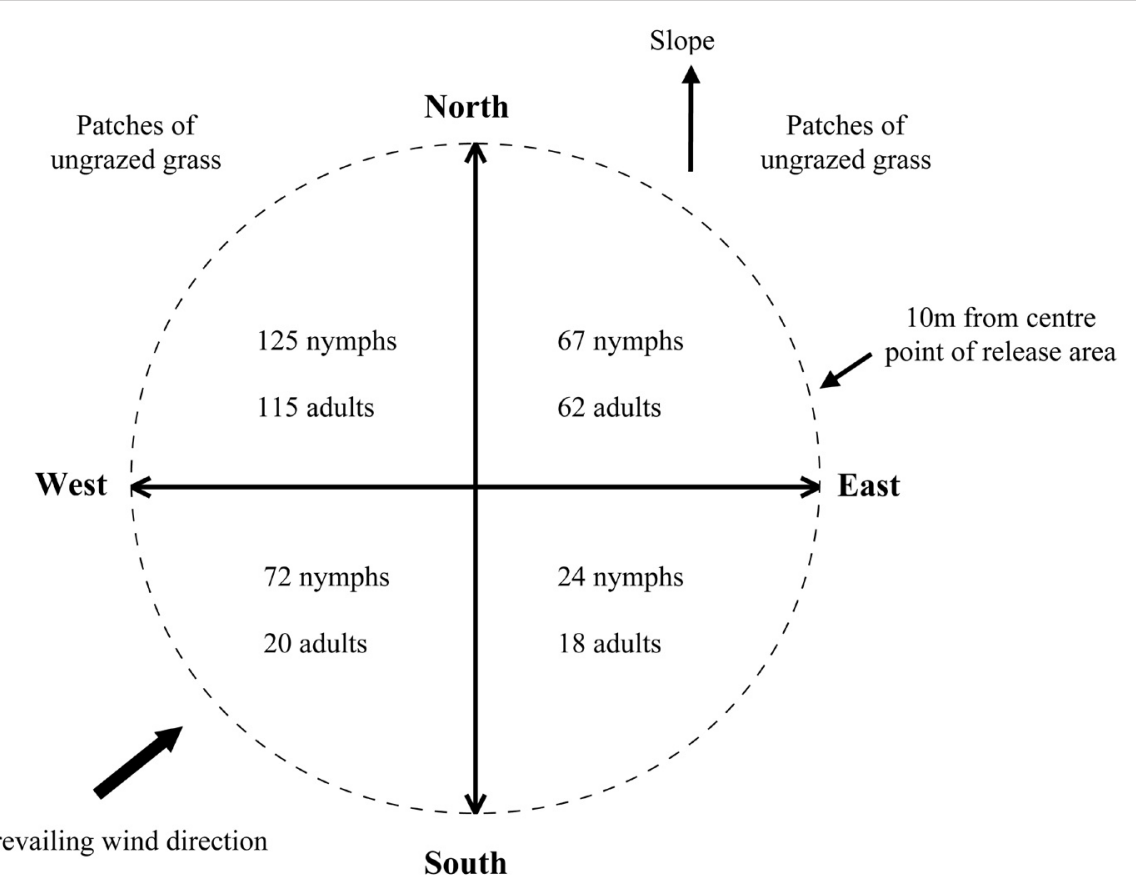

proportions of the marked population. Evidence of the need for dispersal in this heavily grazed pasture was demonstrated by observations at $1800 \mathrm{~h}$ ( $8 \mathrm{~h}$ after release), showing more nymphs and adults resighted outside the release area than inside (Table 2).

Horn (1984) suggested that dispersal of grasshoppers is favored when the local environment is deteriorating, especially if more suitable conditions exist in other adjacent areas. Tall, ungrazed grass outside of the release circle was located uphill within $3 \mathrm{~m}$ to the northeast and northwest, but not present to the south (Figs 2, 3 ). It is suggested that the pattern of uphill dispersal towards the tall, ungrazed patches of vegetation to the northeast and northwest relates to the insect seeking a niche rich in nutrients and potentially suitable for reproduction. Furthermore patches that form in areas contaminated by faeces or in latrines are avoided by the majority of grazing livestock and have tallervegetation (Duffey et al. 1974,Ausden \& Treweek 1995). Grasshoppers may actively seek out these areas for shelter and breeding sites in particularly unfavorable pastures. However, these patches of tall grass are only a temporary habitat and may be removed at any time if grazing pressure increases, which may lead to frequent movements of grasshoppers between favorable areas of tall grass and potentially unfavorable areas in relation to the rate of defoliation by the grazing animal.

The tall, ungrazed patches were at least $5 \mathrm{~m}$ from the center of the release area in the northeast and northwest quadrants (Fig. 2). For successful migration, grasshoppers must have had some indication of the favorable habitat in this direction. The compound eyes of orthopteroids are quite efficient at detecting movement (Marshall \& Haes 1988) and it is reasonable to suggest grasshoppers can detect the long grass by its movement in the wind. Grasshoppers are able to judge the distance of long grass and singing perches by undertaking peering movements whilst assessing the suitability of a patch of vegetation (Chapman 1998). Nymphs and adults may have been able to quickly assess distance and direction of suitable ungrazed patches of grass using their extensive $360^{\circ}$ vision (Chapman 1998), particularly as peering movements would be unobscured by tall vegetation structures in the heavily grazed release circle. Further neurobiological and behavioral research is needed to determine whether grasshoppers such as $C$. parallelus can see patches of suitable habitat and orient towards them. For example, can grasshoppers differentiate between sparse and dense patches of grass in grazed pastures?

Other factors may also have played a role in the dispersal of $C$. parallelus at the study site. Sheep were grazing throughout the experiment and may have disturbed marked individuals, leading to greater dispersal in a particular direction or they may even have acted as a transportation mechanism (Fischer et al. 1996). Disturbance to individuals by the observer was also caused during the resighting process and this may have led to increased dispersal. These factors combined with the small scale of the study mean that the results should be viewed with caution.

Much more work, especially on the long-term dispersal of $C$. parallelus in the UK is needed to determine the habitat features required to enable grasshoppers to successfully colonise reconstructed grasslands, especially on agricultural land where there is a dearth of grasshoppers (Gardiner et al. 2002).

The authors experienced many problems in the selection of a suitable study site. The extensive pasture chosen for this experiment was far from ideal due to uneven topography, variable sward height and microclimatic differences between grazed and ungrazed areas. We found it difficult to make any profound inferences from the data when so many interacting variables could have influenced the results. Perhaps the only way to produce a true assessment of the cues for directional dispersal is to undertake experiments under controlled laboratory conditions of constant temperature, light intensity, and habitat structure.

\section{Conclusion}

Local movements of nymphs and adults were directional with a particular preference for moving to the northwest of the release area. These directional movements were probably in response to the patches of tall, ungrazed grass to the northwest, which should provide a more favorable breeding habitat than the heavily grazed grass of the release area. These patches of tall grass are most likely to be present in lightly grazed extensive pastures because the low numbers of livestock lead to increased structural variation in the sward (Ausden \& Treweek 1995). 


\section{Acknowledgements}

The authors wish to thankWrittle College for funding this project. Thanks are also extended to 2 anonymous referees and Dr. Glenn Morris whose comments were extremely constructive and helpful in revising this paper.

\section{References}

Ausden M., Treweek J. 1995. Grasslands pp. 197-229. In: Sutherland, W.J. \& Hill, D.A. (Eds) Managing Habitats for Conservation. Cambridge University Press, Cambridge.

Chapman R.F. 1998. The Insects, Structure and Function ( $4^{\text {th }}$ edition). Cambridge University Press, Cambridge.

Duffey E., Morris M.G., Sheail J., Ward L.K., Wells D.A., Wells T.C.E. 1974. Grassland Ecology and Wildlife Management. Chapman \& Hall, London.

File D. 1991. Weather Facts. Oxford University Press, Oxford.

Fischer S.F., Poschlod P., Beinlich B. 1996. Experimental studies on the dispersal of plants and animals on sheep in calcareous grasslands. Journal of Applied Ecology 33: 1206-1222.

Gardiner T., Pye M., Field R., Hill J. 2002. The influence of sward height and vegetation composition in determining the habitat preferences of three Chorthippus species (Orthoptera: Acrididae) in Chelmsford, Essex, UK. Journal of Orthoptera Research 11: 207-213.

Homberg U. 2004. In search of the sky compass in the insect brain. Naturwissenschaften 91: 199-208.

Horn H.S. 1984. Some theories about dispersal, pp. 54-62. In: Swingland I.R., Greenwood P.J. (Eds) The Ecology of Animal Movement. Clarendon Press, Oxford.

Labhart T., Meyer E.P. 1999. Detectors for polarized skylight in insects: a survey of ommatidial specializations in the dorsal rim area of the compound eye. Microscopy Research \& Technique 47: 368-379.

Labhart T., Meyer E.P. 2002. Neural mechanisms in insect navigation: polarization compass and odometer. Current Opinions in Neurobiology 12: 707-714.

Labhart T. 1999. How polarization-sensitive interneurones of crickets see the polarization pattern of the sky: a field study with an opto-electronic model neurone. Journal of Experimental Biology 202: 757-770.

Lockwood D.R. 2004. Investigating the dynamics of rangeland grasshopper jumping [www document]. http://www.itd.ucdavis.edu/ dale/studies/ jump.html (accessed 19 January 2004).

Malcolm J. 1926. Agricultural Surveying Including Mensuration, Road Construction and Drainage. University Tutorial Press Ltd, London.

Mappes M., Homberg U. 2004. Behavioral analysis of polarized vision in tethered flying locusts. Journal of Comparative Physiology 190: 61-68.

Marshall J.A., Haes E.C.M. 1988. Grasshoppers and Allied Insects of Great Britain and Ireland. Harley Books, Colchester.

Mead R., Curnow R.N., Hasted A.M. 1993. Statistical methods in agriculture and experimental biology ( $2^{\text {nd }}$ edition). Chapman \& Hall, London.

Narisu, Lockwood J.A., Schell S.P. 1999. A novel mark-recapture technique and its application to monitoring the direction and distance of local movements of rangeland grasshoppers (Orthoptera: Acrididae) in the context of pest management. Journal of Applied Ecology 36: 604-617.

Narisu, Lockwood J.A., Schell S.P. 2000. Rangeland grasshopper movement as a function of wind and topography: implications for pest management. Journal of Orthoptera Research 9: 111-120.

Richards O.W., Waloff N. 1954. Studies on the biology and population dynamics of British grasshoppers, Anti-Locust Bulletin 17: 1-182.

Rogers D. 1984. Pattern and process in large-scale animal movement, pp. 160-180. In: Swingland I.R., Greenwood P.J. (Eds) The Ecology of Animal Movement. Clarendon Press, Oxford.

Samways M.J. 1994. Insect Conservation Biology. Chapman \& Hall, London.
Smith H., Feber R.E., Johnson P.J., McCallum K., Plesner Jensen S., Younes M., Macdonald D.W. 1993. English Nature Science No. 18: The conservation management of arable field margins. English Nature, Peterborough.

Southwood T.R.E., Waloff N. 1967. The experimental approach to animal ecology, pp. 147-159. In: Lambert J.M. (Ed.) Teaching of Ecology. Blackwell Scientific, Oxford.

SPSS. 1999. SPSS version 10. SPSS Inc, Chicago.

Taylor L.R., Taylor R.A.J. 1984. Insect migration as a paradigm for survival by movement, pp. 181-214. In: Swingland I.R., Greenwood P.J. (Eds) The Ecology of Animal Movement. Clarendon Press, Oxford.

Uvarov B. 1977. A handbook of general Acridology. Vol. 2: Behaviour, ecology, biogeography population dynamics. Centre for Overseas Pest Research, London.

Williams C.B. 1958. Insect Migration. Collins, London. 